\title{
Direito e ciência na teoria pura do direito E o problema da liberdade em Kelsen ${ }^{1}$
}

\section{Law and science in the pure theory of law And the problem of freedom in Kelsen}

DOI: 10.54018/sssrv2n1-002

Recebimento dos originais: 07/01/2021

Aceitação para publicação: 29/01/2021

\section{Flávio Marcelo Rodrigues Bruno}

Pós-Doutor em Direito (Universitá degli Studi di Messina-ITA). Doutor em Direito (PPGD/UERJ-RJ). Mestre em Direito (PPGD/Puc-PR). Mestre em Economia (PPGE/Unisinos-RS). Especialização em Direito e Economia (PPGDPPGE/UFRGS). Líder do Grupo de Pesquisa "Direitos Fundamentais, Socioambientalismo e a Ordem Jurídica Internacional". Professor do Curso de Graduação em Direito e Pesquisador Credenciado ao Programa de PósGraduação em Ciências Humanas e Sociais - PPGCS, da Universidade Federal do Oeste da Bahia -UFOB.

Sumário: Introdução. 1. Da relação entre o homem e a natureza. 2. Do Direito Socioambiental e as sociedades tradicionais. 3. O Oeste Baiano e as suas sociedades tradicionais. Considerações Finais. Referências.

\section{RESUMO}

O estudo destina-se a abordar a relação entre o direito e a ciência na Teoria Pura do Direito e o problema da cientificidade na literatura de Hans Kelsen, inicia-se a abordagem com a análise entre a norma jurídica e a proposição jurídica, após uma realiza-se uma abordagem entre a causalidade (ser) e a imputação (dever-ser), expõe-se a ideia kelseneana de norma fundamental e por fim, coloca-se o complexo problema da liberdade na obra deste importante autor da literatura jurídica concluindo que o respostas a este problema só serão encontradas quando atendidas as exigências da ciência. O que se observa é que a norma fundamental defendida por Kelsen é necessária sim para o teórico do direito, aquele que tem a função de explicar a validade do direito, explicar de onde vem a força do direito se do ser ou do dever-ser, ou seja, de um fato ou de uma norma -, mas não para o prático do direito, pois a norma fundamental, como já frisado, é uma norma hipotética, não tem conteúdo, e é justamente disso que precisam os operadores do direito para aplicarem a norma.

Palavras-Chave: Teoria Pura do Direito. Hans Kelsen. Norma Jurídica. Ciência Jurídica. Liberdade.

\footnotetext{
1 Versão ampliada e revisada da originalmente publicada na coletânea, "Transversalidade no Direito: debate transversal no Direito Contemporâneo"- organizada por Raimundo Giovanni França Matos e Flávio Marcelo Rodrigues Bruno, lançada pela Editora L. Andrade, em Aracaju, 2015.
} 


\section{ABSTRACT}

The study is intended to address the relationship between law and science in the Pure Theory of Law and the problem of scientificity in Hans Kelsen's literature. an approach is made between causality (being) and imputation (should-be), it exposes the Kelsenean idea of fundamental norm and, finally, the complex problem of freedom in the work of this important author of legal literature is presented, concluding that the answers to this problem will only be found when the demands of science are met. What is observed is that the fundamental norm defended by Kelsen is indeed necessary for the legal theorist, who has the function of explaining the validity of the law, explaining where the force of law comes from - whether of being or of the should-be, that is, of a fact or a norm -, but not for the legal practitioner, as the fundamental norm, as already emphasized, is a hypothetical norm, has no content, and this is precisely what the operators of the law need to apply the standard..

Keywords: Pure Theory of Law. Hans Kelsen. Legal Standard. Legal Science. Freedom.

\section{INTRODUÇÃO}

Este estudo tem a pretensão de analisar a afirmação de que "a ciência jurídica procura apreender o seu objeto do ponto de vista do Direito" trazida por Hans Kelsen em sua obra Teoria Pura do Direito. Trata-se de uma concepção de ciência jurídica com a qual se pretendia ter alcançado, no Direito, os ideais de toda a ciência, quais sejam, a objetividade e a exatidão. Para alcançar esses objetivos, Kelsen propôs uma depuração do objeto da ciência jurídica, para garantir a autonomia científica para a disciplina jurídica que, segundo ele, vinha sendo deturpada pelos estudos sociológicos, políticos, psicológicos e filosóficos.

Também se propõe a análise de que o pensamento kelseneano pretendia uma ciência das normas que atingisse seus objetivos epistemológicos de neutralidade e objetividade. Era preciso expulsar do ambiente científico os juízos de valor, como já o haviam feito as demais disciplinas científicas. Pretendendo atingir a autonomia disciplinar para a ciência jurídica.

Verificar-se-á que na obra Teoria Pura do Direito, Hans Kelsen definiu o objeto da ciência do direito como constituído em primeiro lugar pelas normas jurídicas e mediatamente pelo conteúdo dessas normas, ou seja, pela conduta humana regulada por estas. Enquanto se estudam as normas reguladoras da conduta - o Direito como um sistema de normas em vigor - fica-se no campo de uma teoria estática do Direito. Mas se o objeto do estudo desloca-se para a conduta humana regulada o processo jurídico em seu movimento de criação e 
aplicação, realiza-se a teoria dinâmica do Direito.

Analisa-se também a questão o princípios da imputação e da causalidade que possuem funções análogas e determinam o ser e o dever-ser na abordagem kelseneana, coloca-se a ideia de norma fundamental de Kelsen, finalizando o estudo com a abordagem do problema da liberdade na obra de Kelsen, quando verificar-se-á que o autor busca superar as elaborações substantivas na dicotomia bem-mal e de um dualismo que pretende constituir o verdadeiro ser da organização de todo o complexo físico e psicológico-físico das relações humanas, e também a busca de numa própria procura de uma forma de se pensar a liberdade que seja a expressão racional para dimensioná-la, ou uma, por assim dizer, "liberdade pela ciência".

\section{A NORMA JURÍDICA E A PROPOSIÇÃO JURÍDICA}

A relação entre direito e ciência na Teoria Pura do Direito de Hans Kelsen começa pela definição do objeto da ciência do direito, que para ele é constituído em primeiro lugar pelas normas jurídicas e mediatamente pelo conteúdo dessas normas, ou seja, pela conduta humana objeto de sua regulação. Assim, enquanto se estudam as normas reguladoras da conduta, o Direito como um sistema de normas em vigor, apresenta-se no campo de uma teoria estática do Direito. Ao passo que, se o objeto do estudo for a conduta humana regulada, o processo jurídico em seu movimento de criação e aplicação, apresenta-se na denominada teoria dinâmica do Direito. É relevante considerar que a dinâmica está subordinada à estática por uma relação de validade formal, pois os atos da conduta humana que desencadeiam o movimento do Direito são os próprios conteúdos das normas jurídicas, e só nesta medida é que interessam para 0 estudo da ciência jurídica, desta forma, o que existe de fato é um dualismo aparente.

Kelsen apresenta o ordenamento jurídico positivo - conjunto das normas válidas - como uma pirâmide de normas, onde se articulam o aspecto estático e o aspecto dinâmico do Direito. A noção de validade formal é o elemento que integra esses dois aspectos, pois, nessa articulação, cada norma retira de uma outra que Ihe é superior, na escala hierárquica do ordenamento jurídico, a sua existência e a sua validade. Assim, por exemplo, no momento em que é criada ou aplicada 
(dinâmica), para que seja considerada válida a norma, é preciso verificar se as condições de sua produção ou aplicação (capacidade e/ou competência dos agentes, além do procedimento de produção e aplicação) estão previamente contidos nos comandos de outras normas já produzidas e integrantes do ordenamento jurídico (estática). O ponto final dessa cadeia de validade é o que Kelsen chama de norma fundamental - pressuposto lógico do sistema normativo (KELSEN, 1998, p. 58).

Segundo Kelsen, a ciência jurídica representa uma interpretação normativa dos fatos:

\begin{abstract}
"Descreve as normas jurídicas produzidas através de atos de conduta humana e que hão-de ser aplicadas e observadas também por atos de conduta e, consequentemente, descreve as relações constituídas, através dessas normas, entre os fatos por elas determinados" (KELSEN, 1998, p. 80).
\end{abstract}

A diferença conceitual entre proposições jurídicas da ciência, que são os juízos hipotéticos que enunciam que, de acordo com o ordenamento, sob certas circunstâncias ali previstas, devem ocorrer certas consequências também previstas por este ordenamento e normas jurídicas, que não são juízos acerca de uma realidade externa, mas sim mandamentos que encerram comandos, permissões e atribuições de poder ou de competência e, desta forma, estabelecida pelas funções: descritiva, da ciência e prescritiva, do Direito. É que, para Kelsen, a ciência não produz Direito, não possui essa função criadora, pois limitada ao papel de conhecimento do Direito produzido pela autoridade jurídica, isto é, por aquele a quem o ordenamento atribui capacidade ou competência para produzir normas jurídicas, na relação entre estática e dinâmica do Direito, que aprendemos como a teoria dogmática das fontes do Direito.

Kelsen situa essa distinção entre ciência jurídica e Direito no plano da validade formal, afastando do campo do Direito as questões relativas à veracidade ou falsidade de seus imperativos de conduta:

\footnotetext{
"A distinção revela-se no fato de que as proposições normativas formuladas pela ciência jurídica, que descrevem o Direito e que não atribuem a ninguém quaisquer deveres ou direitos, poderem ser verídicas ou inverídicas, ao passo que as normas de dever-ser, estabelecidas pela autoridade jurídica - e que atribuem deveres e direitos aos sujeitos jurídicos - não são verídicas ou inverídicas, mas válidas ou
} 
inválidas, tal como também os fatos da ordem do ser não são quer verídicos, quer inverídicos, mas apenas existem ou não existem, somente as afirmações sobre esses fatos podendo ser verídicas ou inverídicas" (KELSEN, 1998, p. 82).

Ao realizar esse deslocamento, Kelsen atrai para as proposições da ciência jurídica a aplicação dos princípios lógicos, uma vez que não sendo as normas jurídicas passíveis de comprovação de sua verdade ou falsidade, não se poderia colocar diretamente relacionado a elas o problema do conflito ontológico entre prescrições. É a ciência que se encarrega de resolver os problemas, o que lhe garante dignidade ou utilidade prática, caso contrário, teria apenas o caráter de repetir os preceitos normativos já estabelecidos anteriormente.

\section{A CAUSALIDADE E A IMPUTAÇÃO}

$\mathrm{Na}$ modernidade, a ciência, impulsionada pelo racionalismo e pelo empirismo, pretendeu ter emancipado o conhecimento "verdadeiro" acerca dos fatos naturais e sociais dos legados místicos que caracterizavam o saber antigo. Para tanto, invertendo a ordem do conhecimento estabelecido, que buscava a solução para os problemas nas verdades absolutas e nos argumentos de autoridade, voltou sua atenção para os próprios fenômenos, no sentido de identificar e descrever, em meio ao aparente caos dos fatos, as regularidades, isto é, a verdadeira ordem das coisas. Sua principal arma metodológica foi a aplicação do método indutivo para a elaboração de proposições científicas fundadas no pressuposto de que a natureza possui uma ordem que pode ser descrita em linguagem rigorosamente técnica. O princípio explicativo dessa ordem natural passa a ser o princípio da causalidade, que se presta apenas à descrição isenta, imparcial, de como as coisas realmente são, de como, sob certas circunstâncias, determinado fato como causa será responsável pela ocorrência de um outro determinado fato, como seu efeito. Em tal concepção, não há espaço para perguntas do tipo teleológicas, finalísticas ou autoritárias.

Essa revolução no conhecimento, promovida pelo paradigma científico, foi assim explicada por Rubem Alves, na obra Filosofia da Ciência:

\footnotetext{
"Explicar alguma coisa em função da pergunta para quê? é compreendêla em função de seus propósitos, objetivos, finalidades. (...) Se o que fazemos se explica teleologicamente, não se deverá concluir que a grande obra da divindade, o universo, deve se explicar em função de seu
} 
propósito? É claro. Se se admite que a natureza é um produto da ação criadora de Deus, a expressão mais alta da sabedoria é ter consciências dos propósitos do Criador. E foi assim que as perguntas teleológicas foram feitas à natureza e as respostas obtidas serviram para dar sentido à vida das pessoas. Só havia um pequeno problema com elas: belas esteticamente, fascinantes psicologicamente, mas irremediavelmente à mercê das idiossincrasias da subjetividade. Elas não podiam ser testadas e corrigidas.

'O livro da natureza está escrito em caracteres matemáticos' (Galileu, II Saggiatore). De fato, momento crucial na história da ciência. Mais do que isso: declaração subversiva, digna da inquisição. Que afirmava Galileu? Que o universo não tem um sentido humano. Por meio dessa afirmação, ele arranca a natureza do quadro quente e amigo marcado pelo amor e pela sabedoria divina, e a coloca num mundo frio em que dominam as relações entre os números. No mundo dos números não se pode mais fazer a pergunta acerca da finalidade do universo" (ALVES, 2000, pp. 86-87).

Em Kelsen, o que se denomina princípio da imputação tem, nas proposições jurídicas, função análoga à do princípio da causalidade em relação às leis naturais. Tal qual uma lei natural, também uma proposição da ciência jurídica liga entre si dois elementos: se " $A$ " é, " $B$ " é (causalidade); se " $A$ " é, " $B$ " deve ser (imputação). A diferença consiste, no entanto, no fato de que, na proposição da ciência jurídica, a ligação entre os elementos fáticos é produzida por uma norma jurídica, isto é, por um ato de vontade autorizado².

A norma jurídica, assim como qualquer norma, não tem a finalidade de descrever os fatos sociais, no caso, as condutas humanas, pelo contrário, ela representa uma interferência na ordem natural ou social desses fatos, qualificando imperativamente as condutas a que se refere.

Kelsen ressalva, ou alerta, que embora se utilize da expressão dever-ser, o sentido dessa expressão traz na proposição da ciência jurídica um caráter meramente descritivo, ainda que o objeto dessa descrição - a norma jurídica - não seja um fato da ordem do ser, mas também um dever-ser. O jurista apenas descreve o Direito; assim como o físico em relação ao seu objeto, ele apenas afirma a ligação entre dois fatos. E mesmo considerando que o objeto da ciência jurídica seja constituído pelas normas e, portanto, pelos valores ali inscritos, as

2 Segundo Kelsen as relações constituídas juridicamente, embora análogas (estabelecem uma conexão funcional entre fatos), não caracterizam a relação causal de fatos do mundo natural. É que no mundo da natureza - explica - um determinado fato será a causa de outro fato (efeito), que por sua vez será causa de outro fato, numa cadeia interminável de causalidades, nos dois sentidos. Coisa diversa ocorre com a imputação, na qual o número de elos da cadeia imputativa se esgota na realização de cada qualificação normativa das condutas. 
proposições científicas, assim como as leis naturais, enfatiza Kelsen, são uma descrição alheia a valores.

Ainda raciocinando analogicamente, Kelsen compara as leis naturais, elaboradas pela Física, enquanto descrição da ordem natural (ser), com as proposições descritivas da ordem jurídica, produzidas pela ciência jurídica, que ele então denomina leis jurídicas, que não são propriamente as normas jurídica (dever-ser), mas apenas a sua descrição científica.

Há momentos, na obra de Kelsen, em que não se sabe de que lado está o quê, principalmente quando o autor recorre à analogia com as ciências naturais para justificar as funções que reputa idênticas àquelas da ciência jurídica, ou seja, a descrição de seus respectivos objetos de conhecimento: os fatos da ordem natural (ser) e as normas jurídicas (dever-ser).

Parece, desta forma, residir sob este aspecto uma confusão, pois para Kelsen, embora sejam realidades ontologicamente diversas, prestam-se ao mesmo tipo de apreensão cognitiva, isto é, podem ser descritas pelo conhecimento científico, desde que, entretanto, sejam aplicados princípios explicativos diferentes: causalidade e imputação, identificando-se como ciências diferentes, peculiares, mas que comungam da mesma metodologia positivista.

Diz Kelsen:

\begin{abstract}
"Assim como a lei natural é uma afirmação ou enunciado descritivo da natureza, e não o objeto a descrever, assim também a lei jurídica é um enunciado ou afirmação descritiva do Direito, a saber, da proposição jurídica formulada pela ciência do Direito, e não o objeto a descrever, isto é o Direito, a norma jurídica. Esta - se bem que quando tem caráter geral seja designada como 'lei' não é uma lei, não é algo que, por qualquer espécie de analogia com a lei natural, possa ser designado como 'lei'. Ela não é, com efeito, um enunciado pelo qual se descreve uma ligação de fatos, uma conexão funcional. Não é sequer um enunciado, mas o sentido de um ato com o qual se prescreve algo e, assim, se cria a ligação entre fatos, a conexão funcional que é descrita pela proposição jurídica, como lei jurídica" (KELSEN, 1998, p. 90)
\end{abstract}

Mesmo toda a preocupação com a pureza não livra Kelsen do envolvimento de sua concepção de ciência com o mundo essencialmente político da produção de normas. Ainda que ele ressalve que a autoridade criadora, seja o juiz ou o legislador, deva conhecer o Direito, valendo-se pois do trabalho do jurista 
científico apenas como uma etapa preliminar de seu processo criativo e decisório.

Um relevante desdobramento da formulação kelseneana é assim procurar desviar do Direito para a sua ciência as questões - tão caras aos cientistas naturais - relativas ao controle de seus postulados, a partir de critérios de verdade e de falsidade, de identidade e de não-contradição. E aqui transparece mais uma vez a crença do autor na pureza de seu objeto, a norma jurídica formalmente válida, nada podendo ser dito acerca de sua verdade ou falsidade - que no direito seria a compatibilidade dessa normatividade com critérios valorativos -, pois este é exatamente o ônus suportado pela ciência jurídica, eu diria, esta é, afinal, sua dignidade.

\section{A NORMA FUNDAMENTAL}

Kelsen, transformou a ciência jurídica em uma ciência pura de normas. Para o autor, a norma não se confunde com o ato de vontade, nem sua existência dele depende, porque as normas valem, têm um valor, sendo a vontade do autor da norma apenas uma condição, mas não a sua razão essencial.

Fábio Ulhoa Coelho, analisando o pensamento de Kelsen, dispôs que:

"Cada norma vale não porque seja justa, ou porque seja eficaz a vontade que a institui, mas porque está ligada a normas superiores por laços de validade, numa série finita que culmina numa norma fundamental" (COELHO, 1996, p. 16).

Diz respeito à teoria da norma fundamental formulada por Hans Kelsen, teoria essa que provocou muita discussão no meio jurídico, pois para seu autor, a teoria constituía o fundamento da ordem jurídica. Para ele uma norma só seria considerada jurídica e legítima se fosse estabelecida em conformidade com as prescrições contidas na norma fundamental.

A norma hipotética fundamental, foi criada por Kelsen com o objetivo de solucionar a questão do fundamento último de validade das normas jurídicas. De acordo com Fábio Ulhoa Coelho, a norma fundamental não é positiva, mas prescreve a obediência aos editores da primeira Constituição histórica. Diz ele:

"Ao se indagar, contudo, sobre a validade da Constituição - a norma jurídica de que decorre a validade das demais -, ela deve forçosamente pressupor a existência de uma norma fundamental, que imponha a observância da mesma Constituição e das normas jurídicas por ela 
Estudando Kelsen e analisando a referida teoria, pode-se identificar e conceituar o que viria a ser essa norma fundamental, uma vez que, nos ensinamentos quotidianos sobre o direito, aprende-se que numa ordem de hierarquia, a Constituição Federal viria como a fonte principal do direito. Neste caso, poderia se perguntar se a Carta Magna seria essa norma fundamental ou se essa norma seria uma ficção.

A hierarquia tratada por Kelsen se refere ao fundamento de validade das normas, tomando como base a relação entre a regra que regula a produção de outra e a regra assim regularmente produzida. Segundo Oliveira Ascensão (1994, p. 465), a norma que regula a produção é a norma superior e a norma produzida segundo as determinações daquela é a norma inferior.

Kelsen coloca no topo dessa hierarquia a norma fundamental que é considerada hipotética, mas ao mesmo tempo, considerada a razão de validade de todo o sistema. De acordo com o autor, essa norma fundamentaria imediatamente as normas que regulam a produção de regras jurídicas gerais, e por sua vez, estas disciplinam a produção de outras regras, sucessivamente, até se consumar a hierarquia.

Outros autores, acreditam que o jurista tem que partir sempre da validade de uma ordem jurídica. Diz Ascensão:

\footnotetext{
"Essa validade depende de uma 'norma fundamental', como a que determinar que 'tudo o que o Estado quer é Direito', que justifica e dá validade a todas as outras. O que quer que seja que não for abrangido por tal norma tem de se reputar não jurídico. Logo, uma ordem jurídica é exclusiva: ela ter validade importa a denegação de validade a todas as outras" (ASCENSÃO, 1994, p. 415).
}

Para Nelson Saldanha (1994, p. 71), a ordem na ótica do direito é composta principalmente de normas, mas no entendimento dele, o direito não consiste apenas na ordem, não se reduzindo a ela. E enfatiza: "A atenção concentrada sobre o problema das normas - aceitas como sendo 'o Direito' ou como parte mais específica dele - fez com que se confundissem as noções de Direito e de ordem (ou 'ordem feita de normas')". 


\section{A LIBERDADE PELA CIÊNCIA}

De acordo com Carrino (1992, p. 211), a literatura aponta para uma constatação de que Kelsen busca superar as elaborações substantivas na dicotomia bem-mal e de um dualismo que pretende constituir o verdadeiro ser da organização de todo o complexo físico e psicológico-físico das relações humanas, e também a busca de numa própria procura de uma forma de se pensar a liberdade que seja a expressão racional para dimensioná-la, ou uma, por assim dizer, "liberdade pela ciência".

Nesse sentido, Kelsen ataca todo espaço da ideologia e do imaginário ideológico-metafísico da organização comunitária, promovendo, com isso, uma "ideologia da aintiideologia" (CARRINO, 1992, p. 210). Tudo isso se torna perceptível em suas confrontações entre o absolutismo e o relativismo na filosofia e na política e ao levar as consequências finais os argumentos jusnaturalistas a respeito da justiça como uma questão teoricamente mal colocada.

Em outras palavras, entende Kelsen que o caráter-limite do absolutismo filosófico é a existência de uma realidade absoluta, uma realidade existencial inacessível e independente do conhecimento humano, pois sua natureza é metafísica; por outro lado, para o relativismo filosófico a realidade apenas existe enquanto objeto do conhecimento humano, com o que a realidade é relativa (KELSEN, 1982, p. 348). Como conseqüência, enquanto para a primeira concepção se supõe haver uma existência absoluta, que resulta numa verdade absoluta, para a segunda apenas há valores que resultam de uma verdade também relativa (KELSEN, 1982, p. 348).

Prosseguindo com suas considerações, Kelsen extrai do caráter metafísico do absolutismo filosófico uma tendência para o monoteísmo religioso e para a idéia de perfeição; já para o relativismo filosófico, por ser antimetafísico, o circunscreve no âmbito do ceticismo (KELSEN, 1982, p. 338). E se o absolutismo filosófico interpreta o mundo em termos solidificados, o resultado obtido apenas pode ser uma desigualdade fundamental dos sujeitos em relação ao absoluto ou supremo; isso, diferentemente do relativismo filosófico, porquanto este refuta as verdade absolutas colocando, todos, no mesmo patamar de iguais, enquanto sujeitos capazes de conhecer.

Com isso, do absolutismo e do relativismo na política e na filosofia, Kelsen 
anuncia a aproximação: "na política..., escreve,...o termo 'absolutismo' designa uma forma de governo em que o poder do Estado concentra-se nas mão de um único indivíduo, ou seja, o governante cuja vontade é a lei" (KELSEN, 1982, p. 350).

Aqui, o poder é ilimitado sendo sinônimo de "despotismo", "ditadura" e "autocracia". Seu oposto - que se identifica com o relativismo filosófico - "é a democracia fundamentada nos princípios de liberdade e de igualdade". Em síntese, "assim como a autocracia é o absolutismo político, e o absolutismo político tem seu paralelo no absolutismo filosófico, a democracia é o relativismo político, assemelhando-se ao relativismo filosófico" (KELSEN, 1982, p. 350).

Portanto, para Kelsen, o absolutismo filosófico se assemelha a concepção do absolutismo político como também ao pensamento primitivo, pois todos remetem a bases metafísicas. Mas há distanciamentos, por certo, entre eles, ainda que recorram ao transcendente: no pensamento primitivo não há diferença entre o aqui e o além, pois ambos constituem uma mesma realidade (KELSEN, 1982, pp. 226-227). Quanto à autocracia, há "aqui" diferente de um "além" em virtude da posição assumida pelo soberano diante das vontades e pensamentos subordinados. De tudo, infere-se que a partir desta comparação, encontra-se no pensamento de Kelsen uma "teologia política" - assunto que alcançou notoriedade nos escritos de Carl Schmitt, principalmente no particular sobre a temática da soberania (SCHMITT, 1988).

No antagonismo dessas duas teorias do Estado fica claro que o contraste das concepções do mundo na qual têm, suas últimas raízes o conflito de opiniões políticas. E tal contraste deriva da posição que se assume nos confrontos do absoluto. O problema decisivo encontra-se nestas alternativas: erigir como valor absoluto, e, pois, uma verdade e realidade absoluta ou assumir que o conhecimento humano pode atingir apenas valores relativos, e, portanto, uma verdade e uma realidade relativas. A fé no absoluto, que encontra raízes profundas no sentimento, constitui o pressuposto de uma concepção de mundo metafísica. A negação, sob o plano intelectivo deste pressuposto, a opinião que existe somente valores relativos e, pois, somente verdades relativas e que, portanto, cada valor e cada verdade - a par do indivíduo que os procura - devem estar sempre preparados para deixar o campo e a deixar substituir. Assim, conduzem a concepção própria do criticismo, do positivismo e do empiricismo, vale dizer, àquela orientação da filosofia e da ciência que faz jus à experiência positiva, isto é, a uma dada experiência, compreensível sob o plano dos sentidos e do intelecto, mutável e sempre em mutação, respondendo assim a ideia do absoluto que transcende a da experiência. Este contraste de concepções de mundo corresponde o contraste de comportamento político fundamental. 
Ou seja: a concepção metafísico-absolutista se associa ao comportamento autocrático; e a concepção crítico-relativista, que é científica, se alia ao comportamento democrático (KELSEN, 1982, p. 56).

Portanto, a ideia da relatividade política está em tudo conforme a relatividade dos valores e com o caráter essencialmente ideológico que Kelsen atribui à política legislativa, pois como expressão desses valores em disputa as normas produzidas podem se tornar antagônicas no tempo histórico, o que está a depender apenas das forças em disputa por seu conteúdo. Além disso, contrariamente ao professado pela fé absolutista, essa relativização enseja um campo de discussão que, fazendo parte da própria ordem normativamente estabelecida, conduz Kelsen a defender a democracia e a tolerância como caminhos racionais de convívio, porque a base do procedimento democrático não é a eleição de um valor absoluto, mas possibilitar a existência de muitos valores em disputa com vistas a sua pontuação.

Sendo assim, as normas não resultam de nenhuma vontade subjetiva sobre-humana, elas resultam das vontades subjetivas humanas, o que corresponde ao rechaço veemente de Kelsen quanto ao direito natural como fundamento possível para o direito, ponto este que lhe exigirá esforços teóricos no sentido de fundamentar o direito terrenamente.

Além disso, outro dado, próximo ao relativismo na política, deve ser neste momento reforçado: a organização social, a ordem política, para Kelsen, não pode ser estabelecida com base no critério subjetivo de justiça, pois as concepções do justo são múltiplas. Dessa forma, embora os valores sejam muitos e diversificados, apenas as normas postas pelos homens podem servir de parâmetro para o convívio.

Portanto, do núcleo argumentativo de Kelsen, chega-se a compreensão de seu sentido, eis que ataca toda forma de alienação, relativisando os valores absolutos. A partir de uma visão do instinto natural do homem (agressivo, egoísta e centrado em si), contesta a racionalidade do medo atávico que leva aos homens a serem comandados por suas projeções psíquicas (que nada mais são do que uma visão poética da vida); desacredita a existência de um Deus da justiça ou de espíritos conformadores (todos interferentes na sociedade humana); e desmente a solução da hipótese de um homem que se quer fazer Deus fazendo-se a si mesmo possuidor da verdade absoluta como um ditador. 
"Ordem", "norma", "Estado", "autoridade": tudo remete a um ponto em comum. Da descrição da superação da luta metafísica entre o bem e o mal, Kelsen, com essa análise, afirma não apenas a autoderminação do homem com respeito ao futuro, mas afirma a sua responsabilidade histórica. Com efeito, a teoria do conhecimento de Kelsen e sua apreciação relativista dos valores com desprendimento de divinizações resulta na opção a favor do compromisso político com o regime democrático, única forma de se lidar com as diferenças sem absolutizações de valores em situação marcadamente de laicização das mentalidades e do Estado.

Em síntese, sob o ponto de vista epistemológico, Kelsen buscará erigir um modelo teórico isento de resquícios metafísicos com o que as teorias tradicionais do Estado com seus dualismos teóricos serão consideradas como herdeiras dos defeitos metodológicos e das contradições de inteligências não libertas pela ciência, e, assim, ainda perturbadas pelo obscurantismo primitivo.

Para Kelsen, a partir do momento em que a razão humana teve condições de entender a natureza e desvenda-la, a autoderminação humana, com respeito ao seu futuro, passou a ser possível, bem como a sua condição humana de compreender a liberdade e a responsabilidade histórica que envolve. Com isso, a resposta do homem para o problema da liberdade, que nada mais é que o problema de como viver com o outro, apenas pode ser obtida satisfatoriamente através de um método que atenda as exigências da ciência.

\section{CONSIDERAÇÕES FINAIS}

A obra Teoria Pura do Direito, de Hans Kelsen, procurou definir as condições para a construção de um conhecimento consistentemente científico do direito. Ele se preocupou com o conhecimento do direito e os meios e métodos que poderiam ser utilizados para assegurar-Ihe o estatuto científico, pois o direito, para ele, nunca deixará de ser ciência. E por ser ciência, precisará sempre ser discutida, analisada, interpretada, com o objetivo de criar mecanismos mais eficazes para os que lidam com essa ciência, ou seja, os operadores do direito.

Como se pode observar da leitura da obra Teoria Pura do Direito, o objetivo de Kelsen era tentar alicerçar na ciência o conhecimento da organização da sociedade estabelecida através de normas, mas ele concluiu pela impossibilidade 
de definição científica do conteúdo das normas jurídicas.

O plano da Teoria Pura era atingir a autonomia disciplinar para a ciência jurídica. Essa é a grande importância do pensamento de Kelsen. Importante destacar que a posição de Kelsen se funda na concepção do direito como ordem coativa da conduta humana, onde uma norma depende de outra conforme a posição hierárquica.

Porém, vimos que a norma fundamental diz apenas que o primeiro legislador age com legitimidade e juridicidade. É apenas, uma norma pensada, hipoteticamente. Não tem existência objetiva. Sendo assim, para que os mandamentos legais possam ser considerados obrigatórios é indispensável supor a existência de uma norma fundamental, que admita a legitimidade do poder e o dever de obediência da comunidade.

Analisando o pensamento de Kelsen, é de se concluir que para ele o direito não é um ato de vontade, motivo que faz com ele seja contra as teorias positivistas tradicionais e também as teorias jusnaturalistas. O direito para Kelsen é um conjunto de prescrições, ou seja, de comandos, por isso que ele fala do direito como ordem normativa de coação, isto é, uma ordem coercitiva que prescreve condutas aos indivíduos.

De uma certa forma, o direito se reveste sim de uma ordem normativa de coação, mas não se pode atribuir a todo o sistema jurídico essa noção, uma vez que ao se falar em ordem deve-se ter a preocupação com um sistema que deve ser um todo unitário e coerente, sem que existam lacunas ou brechas.

O que se observa é que a norma fundamental defendida por Kelsen é necessária sim para o teórico do direito, aquele que tem a função de explicar a validade do direito, explicar de onde vem a força do direito - se do ser ou do deverser, ou seja, de um fato ou de uma norma -, mas não para o prático do direito, pois a norma fundamental, como já frisado, é uma norma hipotética, não tem conteúdo, e é justamente disso que precisam os operadores do direito para aplicarem a norma.

O presente estudo iniciou com a análise do objeto do direito na obra kelseneana, abordando os aspectos estáticos e dinâmicos do direito, perpassando dessa forma a ideia de norma jurídica e proposição jurídica e assim, viu-se que para Kelsen a ciência não produz direito, na relação estática e dinâmica do Direito 
é a ciência que se encarrega da resolução dos problemas, também aborda-se a relação entre ser e dever-ser e traz a ideia kelseneana de norma fundamental para que munidos de uma pré-compreensão sobre estes seja possível analisar o problema da liberdade para Kelsen.

Um dos mais complexos e importantes problemas tratados por Kelsen, sem dúvidas, é o da liberdade e verificamos que a resposta do homem para tal problema, que nada mais é que o problema de como viver com o outro, apenas pode ser obtida através de um método que atenda as exigências da ciência. 


\section{REFERÊNCIAS}

ALVES, Rubem. Filosofia da Ciência - Introdução ao Jogo e a Suas Regras. São Paulo: Loyola, 2000.

ASCENSÃO, José de Oliveira. O direito: introdução e teoria geral: uma perspectiva luso-brasileira. Rio de Janeiro: Renovar, 1994.

CARRINO, A. A ordem da norma, Estado e Direito em Hans Kelsen. São Paulo: Martins Fontes, 1992.

COELHO, Fábio Ulhoa. Para entender Kelsen. São Paulo: Max Limonad Ltda, 1996.

KELSEN, Hans. Teoria Pura do Direito. Trad. João Baptista Machado. 6ª ed. São Paulo: Martins Fontes, 1998.

. Forme di governo e concezioni del mondo. Trad. C. Geracci. Giuffré: Milano, 1982.

MACHADO NETO, A. L. Introdução à Ciência do Direito. 1ำ V. São Paulo: Saraiva, 1960, p. 183.

MOREIRA, Felipe Kern. A ciência do Direito em Hans Kelsen: Abordagem filosófico-crítica. Disponível em: http://www.ambito-juridico.com.br. Acesso em: ago. 2009.

SALDANHA, Nelson. Estudos de Teoria do Direito. Belo Horizonte: Del Rey, 1994.

SCHMITT, Carl. Teologia Política. São Paulo: Struhart, 1998. 